\title{
Anterior Segment Parameters Associated to Acute Glaucoma with Slit Lamp Optical Coherence Tomography
}

\author{
Liamet Fernández Argones, Ibrain Piloto Díaz, Sirley Sibello Deustua, \\ Carmen María Padilla González \\ Glaucoma Department, Cuban Ophthalmology Institute "Ramón Pando Ferrer", Havana City, Cuba \\ Email: lianetfa@infomed.sld.cu
}

Received 17 January 2014; revised 29 March 2014; accepted 30 April 2014

Copyright (C) 2014 by authors and Scientific Research Publishing Inc.

This work is licensed under the Creative Commons Attribution International License (CC BY).

http://creativecommons.org/licenses/by/4.0/

(c) (i) Open Access

\section{Abstract}

Purpose: To identify the anterior segment parameters associated to acute primary angle closure. Patients and Methods: Case-control study in 58 primary angle closure suspect eyes (PACS, control group) and in 19 acute primary angle closure fellow eyes, case group. All subjects underwent SL OCT imaging in a dark room. Results: The SS, ACD and ACV measures were significantly smaller in case group than in control group $(p=0.011 ; p<0.001 ; p=0.007$ respectively); while the IT was significantly greater (at 500 and $750 \mu \mathrm{m})(p=0.038$ and $p=0.050)$. The difference between quadrants were statistically significant only for control group $(p=0.001 ; p=0.003 ; p=0.009 ; p=$ 0.018; $p=0.002$ and $p<0.001$ ) for IS, $A_{C A} A_{500}, A_{0 D} D_{500}, A_{750}, T_{1 S A}$, and TISA $_{750}$ respectively. Conclusion: Acute primary angle closure is associated to the smaller anterior segment dimensions and the thicker iris compared to PACS.

\section{Keywords}

Acute Primary Angle Closure, Acute Glaucoma, Angle Opening Distance, Trabecular-Iris Space Area, Iris Thickness, Optical Coherence Tomography

The acute primary angle closure is an ophthalmological urgency which requires immediate treatment to prevent permanent damaged.

The population studies reveal that more than a half of predispose individuals will not manifest the disease. This reality, the cost of laser prophylactic treatment, the risk of ocular complications and the low accessibility to the technology in some populations justify that proper investigations go on to define the morphological and/or functional factors that determine the acute presentation of the disease [1].

The optical coherence tomography is a high resolution, non invasive technology that offers the possibility to 
obtain anterior segment objective measurements through a cross sectional image.

The aim of this study is to identify the anterior segment parameters associated to acute primary angle closure.

\section{Method}

A case-control study in 58 primary angle closure suspect eyes (PACS, control group) and in 19 acute primary angle closure fellow eyes (case group).

In the control group, only the right eyes with Shaffer grade $<$ or $=1$ in at least two quadrants, intraocular pressure $<21 \mathrm{mmHg}$ with Goldmann tonometer, cup/disc area ratio $<$ or $=0.2$ and absence of peripheral laser iridotomy, were included.

In the case group, the patients with a clinical presentation of a unilateral painful red eye associated to a paralytic mydriasis and intraocular pressure $>40 \mathrm{mmHg}$ were incorporated, whether systemic hypotensive treatment or peripheral laser iridotomy have done. The fellow eyes of these patients have greater probability to develop an acute primary angle closure in the next five years in the absence of a patent peripheral iridotomy [2].

The eyes with previous intraocular surgery, secondary closed-angle glaucoma (cataract, ocular trauma), bilateral acute angle-closure and those with non-optimal tomographic images, were excluded.

The anterior chamber angle was imaged with the slit lamp OCT (SLOCT, Heidelberg Engineering, Germany). The horizontal and vertical scan line bisecting the pupil were achieved with infrared slit lamp illumination and with all room lights switched off.

In each quadrant (nasal, temporal, superior e inferior) the following measures were taken: iris-scleral spur distance (IS), defined as the length of the line segment from the apex of iris recess to the scleral spur; anterior chamber angle (ACA500), defined as the degree of the angle form by a line segment from the apex of iris recess to the internal corneal surface at $500 \mu \mathrm{m}$ of scleral spur and the line from the apex of iris recess which goes through the anterior surface to the iris; angle opening distance, defined as the length of the line segment perpendicular to the corneal endothelium at $500\left(\mathrm{AOD}_{500}\right)$ and at $750 \mu \mathrm{m}\left(\mathrm{AOD}_{750}\right)$ to the iris surface; trabecular-iris space area, define as the cross-sectional area of the angle recess behind the AOD at 500 (TISA 500$)$ and $750 \mu \mathrm{m}$ (TISA $A_{750}$ ), but excluding the area posterior to the sclera spur; and the iris thickness, defined by authors as the line segment from the anterior iris surface to the hyper-reflective posterior iris line at $500\left(\mathrm{IT}_{500}\right)$ and at $750 \mu \mathrm{m}$ $\left(\mathrm{IT}_{750}\right)$ of scleral spur. The iris thickness was measured using the digital gonioscopic software by positioning the AOD segments in the describing place, due to the absence of automatic software to measure the iris thickness (Figure 1) [3]. Other variables studied were: anterior chamber volume (ACV), central anterior chamber depth (ACD), scleral spur-scleral spur distance (SS) and pupil diameter (PD).

To obtain the measurements, the scleral spur was identified by two specialists (LFA, IPD). The automatic software was utilized and the position of calipers was manually adjusted by the operator, if necessary.

The statistic analysis was done by using the SPSS 15.0 software. The independence Ji Cuadrado, the U de Mann-Whitney test and the analysis of variance (ANOVA) were used. It was considered the significance for $\mathrm{p}<$ 0.05 .

The inform consent was obtain from each individuals to get the tomographic images and to use the data in the present investigation, as it is point out in Helsinki's Declaration.

\section{Results}

The distribution of patients according to the age and the color of the skin were similar in both groups. On the other hand, the predisposition of females to acute angle closure was significantly greater $(p=0.023)($ Table 1$)$.

The mean value of the variables that quantified the angle width was smaller for case group. However, the differences were not significant. The pupil diameter was similar in both groups (Table 2).

The anterior chamber depth and volume, and the scleral spur-scleral spur distance were significantly smaller in case group ( $<<0.001, p=0.007$ and $p=0.011$, respectively); while the iris thickness was significantly increased at 500 and $750 \mu \mathrm{m}(\mathrm{p}=0.038$ and $\mathrm{p}=0.050$, respectively) (Table 2).

In the case group the differences were significant only for IS variable $(p=0.039)$, specifically due to differences between nasal and temporal vs. inferior quadrants; although the confidence intervals were too elevated to assure the result.

In the control group, all the variables related to angle width showed significant differences between quadrants $\left(p=0.001 ; p=0.003 ; p=0.009 ; p=0.018 ; p=0.002\right.$ and $p<0.001 ;$ for IS, ACA, AOD $_{500}$, AOD $_{750}$, TISA ${ }_{500}$ and 

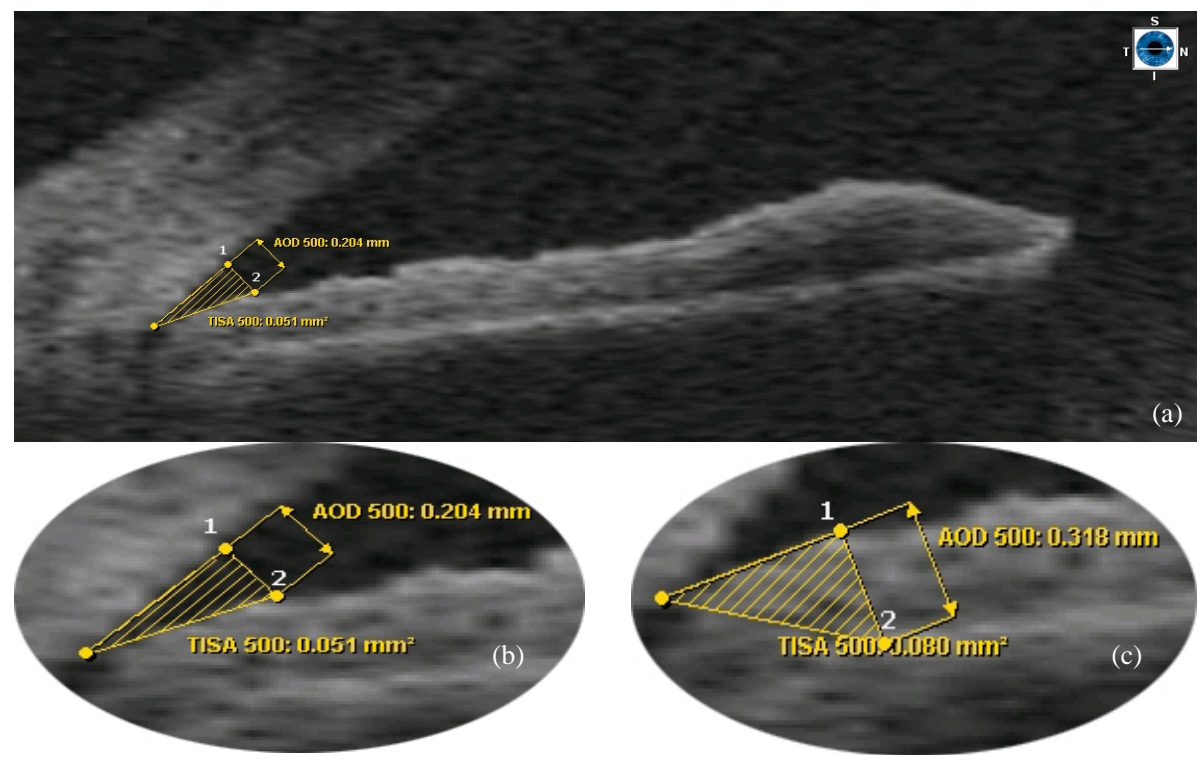

Figure 1. Angle opening distance at $500 \mu \mathrm{m}$ of scleral spur $\left(\mathrm{AOD}_{500}\right)(\mathrm{a})$. The automatic 1 and 2 points for $\mathrm{AOD}_{500}$ (from digital gonioscopy software) are magnified (b) and moved to the anterior iris surface (point 1) and to the hyper-reflective posterior iris line (point 2) to measure the iris thickness (c). The image was taken from Fernández et al. [3].

Table 1. Distribution of patients with PACS eyes (control group, $n=58$ ) and APAC fellow eyes (case group, $n=19$ ) by age, sex and color of the skin.

\begin{tabular}{ccccccc}
\hline Group & Mean age \pm SD (years) & $\mathrm{p}^{*}$ & Sex F:M & $\mathrm{p}^{* *}$ & Color of skin W:NW & $\mathrm{p}^{* *}$ \\
\hline Control $(\mathrm{n}=58)$ & $60 \pm 28.5$ & 0.473 & $3: 1$ & 0.023 & $1: 2$ & 0.078 \\
Case $(\mathrm{n}=19)$ & $62 \pm 24.5$ & & $19: 1$ & & $1: 1$ & \\
\hline
\end{tabular}

SD: standard deviation; F: female: M: masculin; W: white; NW: non-white; $\mathrm{p}^{*}$ : associated to U de Mann-Whitney; ${ }^{* *}$ : associated to Chi-Square test.

Table 2. Optical coherence tomography measurement differences between PACS eyes (control group, $\mathrm{n}=58$ ) and APAC fellow eyes (case group, $\mathrm{n}=19$ ).

\begin{tabular}{|c|c|c|c|}
\hline Variables & Control group Mean \pm SD & Case group Mean \pm SD & $\mathrm{p}^{*}$ \\
\hline IS (mm): & $0.051 \pm 0.045$ & $0.058 \pm 0.056$ & 0.617 \\
\hline $\operatorname{ACA}_{500}\left({ }^{\circ}\right)$ & $12.03 \pm 7.16$ & $10.82 \pm 9.25$ & 0.398 \\
\hline $\mathrm{AOD}_{500}(\mathrm{~mm})$ & $0.104 \pm 0.061$ & $0.091 \pm 0.076$ & 0.315 \\
\hline $\mathrm{AOD}_{750}(\mathrm{~mm})$ & $0.192 \pm 0.087$ & $0.173 \pm 0.118$ & 0.471 \\
\hline TISA $_{500}\left(\mathrm{~mm}^{2}\right)$ & $0.041 \pm 0.026$ & $0.038 \pm 0.031$ & 0.675 \\
\hline $\mathrm{TISA}_{750}\left(\mathrm{~mm}^{2}\right)$ & $0.086 \pm 0.041$ & $0.080 \pm 0.052$ & 0.595 \\
\hline $\mathrm{IT}_{500}(\mathrm{~mm})$ & $0.347 \pm 0.056$ & $0.379 \pm 0.063$ & 0.038 \\
\hline $\mathrm{IT}_{750}(\mathrm{~mm})$ & $0.360 \pm 0.084$ & $0.411 \pm 0.083$ & 0.050 \\
\hline $\operatorname{ACV}\left(\mathrm{mm}^{3}\right)$ & $97.77 \pm 20.72$ & $82.50 \pm 18.92$ & 0.007 \\
\hline $\mathrm{ACD}(\mathrm{mm})$ & $2.32 \pm 0.27$ & $1.97 \pm 0.26$ & 0.000 \\
\hline $\mathrm{PD}(\mathrm{mm})$ & $3.16 \pm 0.99$ & $2.98 \pm 1.04$ & 0.482 \\
\hline SS & $11.575 \pm 0.436$ & $11.239 \pm 0.523$ & 0.011 \\
\hline
\end{tabular}

$\mathrm{p}^{*}$ : associated to U de Mann-Whitney. 
TISA $_{750}$ respectively) (Table 3). The values were greater at nasal and temporal vs. the superior and inferior quadrants.

In both groups, the iris thickness was similar between quadrants (Table 3).

\section{Discussion}

The female predispositions to APAC agree with findings of other studies where the angle width measurements are smaller in women [4] [5].

In the current study, the absence of angle width significant differences between SPAC and APAC fellow eyes are probably justify by the fact that the APAC fellow eyes were included either received laser peripheral iridotomy or systemic ocular hypotensive treatment. It is expected that peripheral iridotomy increase not only the angle width but the volume and the central depth of anterior chamber; while the iris bowing decrease [6]-[9].

Different authors have found an inverse relation between the angle width and the probability of acute primary angle closure. For example, Foo et al. [10] performed a linear regression modeling with trabecular-iris space area at $750 \mu \mathrm{m}\left(\mathrm{TISA}_{750}\right)$ and angle opening distance at $750 \mu \mathrm{m}\left(\mathrm{AOD}_{750}\right)$ from the scleral spur as the two dependent angle width variables; whereas Guzman et al. [11] even identified that the TISA 750 is one of the major determinants of acute angle closure.

The smaller dimensions of the anterior chamber (ACD, ACV and SS) and the increased iris thickness are associated to the acute attack, according to the results of this study. It is likely to occur as the peripheral iris would be in closer proximity to the angle.

Additionally, Amerasinghe et al. [4] confirm that the angle width is smaller in eyes with shallower ACD, which means that the iris-lens diaphragm is more anteriorly located in APAC fellow eyes; so it could be related to the anatomic predisposition to acute primary angle closure. Foo et al. [10] also demonstrated that the angle width is largely dependent on variations in ACV.

Table 3. Optical coherence tomography measurement differences between quadrants in PACS eyes (control group, $\mathrm{n}=58$ ) and APAC fellow eyes (case group, $\mathrm{n}=19$ ).

\begin{tabular}{|c|c|c|c|c|c|c|}
\hline \multicolumn{2}{|c|}{ Variables } & $\begin{array}{c}\text { Nasal } \\
\text { Means } \pm \text { SD }\end{array}$ & $\begin{array}{c}\text { Temporal } \\
\text { Means } \pm \text { SD }\end{array}$ & $\begin{array}{c}\text { Superior } \\
\text { Means } \pm \text { SD }\end{array}$ & $\begin{array}{c}\text { Inferior } \\
\text { Means } \pm \text { SD }\end{array}$ & $\mathrm{p}^{*}$ \\
\hline \multirow{2}{*}{ IS (mm) } & Control & $0.055 \pm 0.060$ & $0.070 \pm 0.068$ & $0.024 \pm 0.042$ & $0.037 \pm 0.045$ & $0.001^{*}$ \\
\hline & Case & $0.068 \pm 0.072$ & $0.073 \pm 0.059$ & $0.026 \pm 0.052$ & $0.017 \pm 0.023$ & $0.039^{* *}$ \\
\hline \multirow{2}{*}{$\mathrm{ACA}_{500}\left({ }^{\circ}\right)$} & Control & $14.04 \pm 8.02$ & $14.33 \pm 8.89$ & $9.56 \pm 9.13$ & $9.28 \pm 8.41$ & $0.003^{*}$ \\
\hline & Case & $12.93 \pm 12.07$ & $9.07 \pm 10.74$ & $5.78 \pm 8.32$ & $6.89 \pm 7.34$ & $0.473^{* *}$ \\
\hline \multirow{2}{*}{$\mathrm{AOD}_{500}(\mathrm{~mm})$} & Control & $0.122 \pm 0.075$ & $0.119 \pm 0.076$ & $0.087 \pm 0.082$ & $0.079 \pm 0.069$ & $0.009^{*}$ \\
\hline & Case & $0.101 \pm 0.085$ & $0.076 \pm 0.089$ & $0.051 \pm 0.076$ & $0.064 \pm 0.076$ & $0.507^{* *}$ \\
\hline \multirow{2}{*}{ AOD750 } & Control & $0.206 \pm 0.102$ & $0.223 \pm 0.096$ & $0.172 \pm 0.109$ & $0.163 \pm 0.106$ & $0.018^{*}$ \\
\hline & Case & $0.179 \pm 0.129$ & $0.165 \pm 0.137$ & $0.105 \pm 0.112$ & $0.115 \pm 0.120$ & $0.392^{* *}$ \\
\hline \multirow{2}{*}{$\mathrm{TISA}_{500}\left(\mathrm{~mm}^{2}\right)$} & Control & $0.046 \pm 0.029$ & $0.051 \pm 0.035$ & $0.030 \pm 0.029$ & $0.032 \pm 0.031$ & $0.002^{*}$ \\
\hline & Case & $0.040 \pm 0.041$ & $0.045 \pm 0.039$ & $0.018 \pm 0.029$ & $0.019 \pm 0.030$ & $0.269^{* *}$ \\
\hline \multirow{2}{*}{$\mathrm{TISA}_{750}\left(\mathrm{~mm}^{2}\right)$} & Control & $0.097 \pm 0.046$ & $0.105 \pm 0.046$ & $0.071 \pm 0.048$ & $0.065 \pm 0.044$ & $0.000^{*}$ \\
\hline & Case & $0.081 \pm 0.064$ & $0.078 \pm 0.064$ & $0.047 \pm 0.046$ & $0.060 \pm 0.063$ & $0.486^{* *}$ \\
\hline \multirow{2}{*}{$\mathrm{IT}_{500}(\mathrm{~mm})$} & Control & $0.333 \pm 0.073$ & $0.335 \pm 0.063$ & $0.358 \pm 0.072$ & $0.364 \pm 0.078$ & $0.091^{*}$ \\
\hline & Case & $0.387 \pm 0.074$ & $0.373 \pm 0.089$ & $0.395 \pm 0.038$ & $0.423 \pm 0.084$ & $0.588^{* *}$ \\
\hline \multirow{2}{*}{$\mathrm{IT}_{750}(\mathrm{~mm})$} & Control & $0.360 \pm 0.093$ & $0.358 \pm 0.076$ & $0.376 \pm 0.086$ & $0.372 \pm 0.101$ & $0.694^{*}$ \\
\hline & Case & $0.411 \pm 0.085$ & $0.417 \pm 0.105$ & $0.435 \pm 0.070$ & $0.470 \pm 0.118$ & $0.650^{* *}$ \\
\hline
\end{tabular}

$\mathrm{p}^{*}$ : associated to Anova; $\mathrm{p}^{* *}$ : associated to Kruskal-Wallis. 
Related to the increased iris thickness, Wang et al. [12] coincide that it is independently associated with angle closure as it have been proposed by several authors [13].

According to the current PACS eyes tomographic images, the angle is wider on temporal and nasal than on superior or inferior quadrants. Similarly, Nolan et al. [14] showed that the inferior angle is closed more frequently than the nasal or temporal quadrants, while Sakata et al. [15] found that the superior quadrant is the narrowest. Besides, Amerasinghe et al. [4] found that the angle is narrower temporally than nasally.

The present study show that there is not angle width differences between quadrants in APAC fellow eyes, which differs from the findings in PACS eyes and the reports mentioned above. It is possible that the narrowest angle in all quadrants may be associated to APAC.

Important limitations of the current study include the fact that changes on the iris area, volume and bowing in both light and dark conditions were not done due to the absence of the appropriate software in the SL-OCT tomography.

Our sample size was relatively small, and some of the differences found may not have been significant due to the limited power.

The acute primary angle closure is associated to female sex, the smaller anterior segment dimensions and the thicker iris compared to PACS.

\section{References}

[1] Friedman, D.S. (2001) Who Needs an Iridotomy? British Journal of Ophthalmology, 85, 1019-1021. http://dx.doi.org/10.1136/bjo.85.9.1019

[2] Friedman, D.S., Gazzard, G. and Foster, P. (2003) Ultrasonographic Biomicroscopy, Scheimpflug Photography, and Novel Provocative Tests in Contralateral Eyes of Chinese Patients Initially Seen with Acute Angle Closure. Archives of Ophthalmology, 121, 633-642. http://dx.doi.org/10.1001/archopht.121.5.633

[3] Fernandez Argones, L., et al. (2011) Modificaciones del segmento anterior ocular posterior a iridotomía láser periférica mediante tomografía de coherencia óptica. Rev Cubana Invest Bioméd, 30, 301-311. http://scielo.sld.cu/scielo.php?script=sci_arttext\&pid=S0864-03002011000300001\&lng=es\&nrm=iso

[4] Amerasinghe, N., Foster, P., Wong, T.Y., Htoon, H.M., He, M., Shen, S.Y., et al. (2009) Variation of Angle Parameters in Asians: An Anterior Segment Optical Coherence Tomography Study in a Population of Singapore Malays. Investigative Ophthalmology \& Visual Science, 50, 2626-2631. http://dx.doi.org/10.1167/iovs.08-2582

[5] Nongpiur, M.E., Sakata, L., Friedman, D.S., He, M., Chan, Y.H., Lavanya, R., et al. (2010) Novel Association of Smaller Anterior Chamber Width with Angle Closure in Singaporeans. Ophthalmology, 117, 1967-1973.

[6] How, A.C., Baskaram, M., Kumar, R.S., He, M., Foster, P.J., Lavanya, R., et al. (2012) Changes in Anterior Segment Morphology after Laser Peripheral Iridotomy: An Anterior Segment Optical Coherence Tomography Study. Ophthalmology, 119, 1383-1387. http://dx.doi.org/10.1016/j.ophtha.2012.01.019

[7] Huang, G., Gonzalez, E., Lee, R., Osmonavic, S., Leeungurasatien, T., He, M., et al. (2012) Anatomic Predictors for Anterior Chamber Angle Opening after Laser Peripheral Iridotomy in Narrow Angle Eyes. Current Eye Research, 37, 575-582. http://dx.doi.org/10.3109/02713683.2012.655396

[8] Lee, R.Y., Kasuga, T., Cui, Q.N., Huang, G., He, M. and Lin, S.C. (2013) Association between Baseline Angle Width and Induced Angle Opening Following Prophylactic Laser Peripheral Iridotomy. Investigative Ophthalmology \& Visual Science, 54, 3763-3770. www.ncbi.nlm.nih.gov/pmc/articles/PMC23661374 http://dx.doi.org/10.1167/iovs.13-11597

[9] Lei, K., Wang, N., Wang, L. and Wang, B. (2009) Morphological Changes of the Anterior Segment after Laser Peripheral Iridotomy in Primary Angle Closure. Eye, 23, 345-350. http://dx.doi.org/10.1038/sj.eye.6703050

[10] Foo, L.L., Nonqpiur, M., Allen, J.C., Perera, S.A., Friedman, D.S., He, M., et al. (2012) Determinants of Angle Width in Chinese Singaporeans. Ophthalmology, 119, 278-282. http://dx.doi.org/10.1016/j.ophtha.2011.07.049

[11] Guzman, C.P., Gong, T., Nonqpiur, M.E., Perera, S.E., How, A.C., Lee, H.K., et al. (2013) Anterior Segment Optical Coherence Tomography Parameters in Subtypes of Primary Angle Closure. Investigative Ophthalmology \& Visual Science, 54, 5281-5286. http://dx.doi.org/10.1167/iovs.13-12285

[12] Wang, B.S., Nongpiur, A. and Amerasinghe, N. (2011) Increased Iris Thickness and Association with Primary Angle Closure Glaucoma. British Journal of Ophthalmology, 95, 46-50. http://dx.doi.org/10.1136/bjo.2009.178129

[13] Quigley, H.A. (2010) The Iris Is a Sponge: A Cause of Angle Closure. Ophthalmology, 117, 1-2. http://dx.doi.org/10.1016/j.ophtha.2009.11.002

[14] Nolan, W.P., See, J.L., Chew, P.T., Friedman, D.S., Smith, S.D., Radhakrishnan, S., Zheng, C., Foster, P.J. and Aung, 
T. (2007) Detection of Primary Angle Closure Using Anterior Segment Optical Coherence Tomography in Asian Eyes. Ophthalmology, 114, 33-39. http://dx.doi.org/10.1016/j.ophtha.2006.05.073

[15] Sakata, L.M., Lavanya, R., Friedman, D.S., Aung, H.T., Gao, H., Kumar, R.S., Foster, P.J. and Aung, T. (2008) Comparison of Gonioscopy and Anterior Segment Ocular Coherence Tomography in Detecting Angle Closure in Different Quadrants of the Anterior Chamber Angle. Ophthalmology, 115, 769-774. http://dx.doi.org/10.1016/j.ophtha.2007.06.030 